\title{
Human papillomavirus DNA detected in peripheral blood samples from healthy Australian male blood donors.
}

\author{
Alice Che-Ha Chen ${ }^{1}$, Annie Keleher ${ }^{1}$, Mary-Anne Kedda ${ }^{2}$, Amanda B. Spurdle ${ }^{3}$, Nigel A.J. McMillan ${ }^{1}$ \\ and Annika Antonsson ${ }^{1 *}$
}

${ }^{1}$ The University of Queensland, Diamantina Institute for Cancer, Immunology and Metabolic Medicine, Princess Alexandra Hospital, Woolloongabba, Brisbane, QLD 4102, ${ }^{2}$ Institute of Health and Biomedical Innovation, Queensland University of Technology, Victoria Park Road, Kelvin Grove, Brisbane, QLD 4059, ${ }^{3}$ Genetics and Population Health Division, Queensland Institute of Medical Research, 300 Herston Road, Brisbane, QLD 4006,Australia.

Running title: HPV DNA in blood samples from healthy males

Keywords: Human papillomavirus, Peripheral blood, Healthy blood donors and Polymerase chain reaction

Manuscript word count: 4.010, number of tables: 1, number of figures: 1

Corresponding author*:

Dr Annika Antonsson, Diamantina Institute for Cancer, Immunology and Metabolic Medicine,

The University of Queensland, Research wing, Building 1, Level 4, Princess Alexandra Hospital, Woolloongabba, QLD 4102, AUSTRALIA.

Phone +6173240 5387, Fax +61732405946, email a.antonsson@uq.edu.au

Funding: This work was supported by the Prostate Cancer Foundation in Australia, the Mazda foundation and the Sir Edward Dunlop Medical Research Foundation.

Editorial Board Members: Zhi-Ming Zheng, Dennis J. McCance and Xiang-Jin Meng.

Conflict of interest: No conflict of interest to report. 


\section{Abstract}

Recent studies have shown that human papillomavirus (HPV)-DNA can be found in circulating blood, including peripheral blood mononuclear cells (PBMCs), sera, plasma and arterial cord blood. In light of these findings, we examined DNA extracted from PBMCs from healthy blood donors in order to determine how common HPV-DNA is in blood of healthy individuals.

Blood samples were collected from 180 healthy male blood donors (18 to 76 years old) through the Australian Red Cross Blood Services. Genomic DNA was extracted and specimens were tested for HPV-DNA by PCR using a broad range primer pair. Positive samples were HPV-type determined by cloning and sequencing.

We found $8.3 \%(15 / 180)$ of our blood donors to be positive for HPV DNA. A wide variety of different HPV-types were isolated from the PBMCs; belonging to the cutaneous beta and gamma papillomavirus genera and mucosal alpha papillomaviruses. High-risk HPV-types that are linked to cancer development were detected in 1.7\% (3/180) of the PBMCs.

We also collected blood from a healthy HPV-positive 44 year-old male on four different occasions in order to determine which blood cell fractions harbour HPV. PBMCs treated with trypsin were negative for HPV, while non-trypsinised PBMCs were HPV-positive. This suggests that the HPV in blood is attached to the outside of blood cells via a protein-containing moiety. We also isolated HPV in the B cells, dendritic cells, NK cells and neutrophils.

We conclude that HPV present in PBMCs could represent a reservoir of virus and a potential new route of transmission. 


\section{Introduction}

To date, over 100 different genotypes of the human papillomaviruses (HPV) have been fully characterized. Infection with HPV can present a wide variety of clinical manifestations of the skin and mucosa, most commonly as warts, either skin or genital (18), although many HPV infections, especially those of the skin, are often without clinical symptoms $(1,2,4)$. The most important HPV-associated disease is undoubtedly cancer. Cervical cancer and many other anogenital cancers are caused by HPVinfections, and many other cancer forms have either been proven or are suspected to be linked to HPV (27).

The papillomaviruses require proliferating basal layer cells and must access the basal cell layer of the epidermis or mucosa to establish infection. Hence, the transmission of HPV is believed to be facilitated by the presence of abraded or macerated epithelial surfaces (18). All papillomavirus genes are transcribed in the epithelia, and the viral particles are assembled and released in the most superficial layers of the epithelium (22). It has long been believed that papillomavirus cannot be spread to different body sites through blood, as papillomaviruses do not give rise to viremia. However, several recent studies have shown that HPV DNA can be found in circulating blood, including peripheral blood mononuclear cells (PBMCs), sera, plasma and arterial cord blood (3, 9, 21, 23, 24). So far, most of these studies have only been conducted in female cancer patients, with relatively small sample sizes. Only mucosal HPV types have been detected in blood, and no active viral replication has been found. The presence of HPV-16 and HPV-18 E6 mRNA in peripheral blood of cervical cancer patients has also been suggested to provide an early biomarker that identifies patients who are at risk for developing metastases (24).

In light of these findings, we wanted to establish if HPV DNA is present in the blood of healthy individuals. We thus examined DNA extracted PBMCs from 180 healthy male Red Cross blood donors and different blood cell fractions from one healthy male. 


\section{Materials and Methods}

\section{Healthy male Red Cross blood donors}

Blood samples were collected from 180 healthy male blood donors, recruited through the Australian Red Cross Blood Services in 2005 in Brisbane, Queensland(17). All participants were Caucasian men between 19 and 76 years of age, and all subjects gave written informed consent. The collection of blood samples for research purposes was approved by the Ethics Committees from the Queensland University of Technology (QIMR; 3630H), the Australian Red Cross Blood Services (2004\#17) and the Queensland Institute of Medical Research (QIMR; P820). Genomic DNA was extracted from peripheral blood cells using the QIAamp DNA Blood Mini Kit (Qiagen, Hilden, Germany) according to the manufacturer's instructions. All samples were analyzed with FAP59/64 and human L1 PCR as described below.

\section{Healthy male blood donor for blood cell separation study}

Peripheral blood was collected from a vein in the antecubital space at four different occasions $\left(4^{\text {th }}\right.$ of September, $23^{\text {rd }}$ of October, $6^{\text {th }}$ of November and $4^{\text {th }}$ of December 2008) from a healthy 44-year-old male, in order to determine the types of blood cells in which HPV DNA could be detected.

From the first blood sample $60 \mathrm{ml}$ blood was analysed and peripheral blood mononuclear cells (PBMCs) were isolated with a standard Ficoll blood separation protocol (by density-gradient centrifugation over Histopaque-1077 (Sigma-Aldrich, St Louis, MO)) and red blood cells were lysed using $\mathrm{NH}_{4} \mathrm{Cl}$ ghosting. MACS® $\mathrm{CD} 19$ MicroBeads (Miltenyi Biotec GmbH, Bergisch Gladbach, Germany) were then used to further separate B cells from the rest of the PBMCs using an Auto ${ }^{\text {TMMac }}$ pro Separator (Version 1.1; Miltenyi Biotec $\mathrm{GmbH}$ ) according to the manufacturer's protocol. DNA from the two cell fractions was extracted using Qiagen Blood \& Cell Culture DNA Midi Kit.

For the second blood collection $60 \mathrm{ml}$ was taken, PBMCs were isolated with Ficoll blood separation, red blood cells lysed, and PBMCs were then treated with $5 \mathrm{ml}$ of trypsin for 5 minutes. Thirty $\mathrm{ml}$ of serum (that also contains the platelets) was collected and PBMCs were separated into seven different 
fractions with MACS $^{\circledR}$ MicroBeads (Miltenyi Biotec GmbH). MACS $^{\circledR}$ MicroBeads were used for positive selection of different PBMCs (according to manufacturer's protocol) using the Auto ${ }^{\mathrm{TM}} \mathrm{Mac}$ pro Separator in the following order: B cells, myeloid dendritic cells (mDCs; isolated with CD1c (BDCA1) ${ }^{+}$Dendritic Cells Isolation Kit), T cells (CD3 MicroBeads), NK cells (CD56 MicroBeads), monocytes and macrophages (CD14 MicroBeads) and finally neutrophils (CD66abce MicroBeads Kit). The fraction of PBMCs that were not selected by the MACS $^{\circledR}$ MicroBeads was called flow-through. Qiagen Blood \& Cell Culture DNA Midi Kit was used to extract DNA from each cell type fraction.

Forty $\mathrm{ml}$ of blood was collected at the third occasion and PBMCs were isolated with Ficoll blood separation as described above. After the Ficoll treatment, half of the PBMCs were treated with $5 \mathrm{ml}$ of trypsin for 5 minutes before DNA was extracted using Qiagen Blood \& Cell Culture DNA Midi Kit. The other half of the PBMCs were DNA extracted with the same Qiagen Midi Kit (without previous trypsin treatment).

For the fourth blood collection $60 \mathrm{ml}$ was collected and the PBMCs were isolated as described for the second blood collection, with the only exception that the PBMCs were not treated with trypsin. The PBMCs were then separated into eight different fractions with MACS $^{\circledR}$ MicroBeads as described for the second blood collection, with the exception that the dendritic cells this time were fractioned into mDCs and plasmacytoid dendritic cells (pDCs). The pDCs were isolated using the CD304 (BDCA4/Neuropilin-1) MACS ${ }^{\circledR}$ MicroBead kit. DNA of each cell fractions was extracted using Qiagen Blood \& Cell Culture DNA Midi kit (Qiagen).

To rule out contamination of HPV DNA from the skin surface in the blood samples, swab specimens were collected from four other skin sites when blood was collected at the second, third and fourth blood collection. The four swab samples were collected from; 1 . the skin of the antecubital site before the blood was taken, 2. the antecubital site stripped with tape that was attached five times, then new tape was attached for another five times (sample taken before blood collection), 3. the needle after the blood had been collected and 4. the skin of the forehead. The tape-stripped method aimed to remove 
any possible HPV DNA shed on the skin surface. Pre-wetted cotton-tipped swabs (Q-TIPS, Tyco Healthcare Group LP, Mansfield, MA, USA) were soaked in sterile saline solution $(0.9 \% \mathrm{NaCl})$ and drawn back and forth five times over the skin, and the swab was then suspended in $1 \mathrm{ml}$ saline solution. Samples were analysed directly after collection and then stored at $-20^{\circ} \mathrm{C}$.

\section{HPV DNA detection and typing}

The samples were tested with PCR for HPV DNA with the general primer-pair FAP59/FAP64 (12), using a previously described protocol, except for the $\mathrm{MgCl}_{2}$ concentration, which was modified to 3.5 $\mathrm{mM}$. Furthermore, all samples were analyzed for the presence of the human L1 sequence (8), as a control for human DNA and as an indirect marker to ensure that a sample did not contain any PCRinhibiting substances. Amplified PCR products were analysed by electrophoresis in a 1.5\% agarose gel containing TAE buffer and ethidum bromide (Sigma). PCR amplicons were size determined under UV light using the GelDoc software (Bio-Rad, Sydney, Australia).

PCR products were cloned using a TOPO TA cloning Kit Dual Promoter (Invitrogen, Carlsbad, CA, USA). Samples were ligated into pCR2.1 TOPO cloning vector and transformed into TOP10 Competent Cells (Invitrogen) following the manufacturer's specifications. Clones with inserts were sequenced with both forward and reverse primers (BigDye® Terminator v3.1 Cycle Sequencing Kit; Applied Biosystems, Foster City, CA). The sequences were analysed at the Australian Genome Research Facility Ltd., Brisbane. Sequences obtained were compared with available sequences in the GenBank database using the BLAST server (http://www.ncbi.nlm.nih.gov/BLAST/). 


\section{Results}

\section{Detection of HPV DNA in PBMCs from healthy blood donors}

We found $8.3 \%$ (15/180) of our Red Cross blood donors to be HPV DNA positive and a wide variety of different HPV-types were isolated from the PBMCs. From the mucosal alpha papillomavirus genus we detected HPV-16, HPV-18 (in two blood donors), HPV-27, HPV-32, HPV-70, HPV-97 and HPV102. High-risk HPV-types, like HPV-16 and HPV-18, that are linked to cancer development were detected in $1.7 \%(3 / 180)$ of the PBMCs. From the cutaneous beta papillomavirus genus we isolated HPV-12, HPV-15 and HPV-47, and from the skin gamma genus we identified HPV-48, HPV-65, HPV-FA31 and HPV-FA55. The 15 HPV-positive blood donors ranged from 24 to 67 years of age, which within the range to the entire sample set examined is similar to the blood donors (range 19 to 76 years of age; Table 1).

\section{Isolation of HPV DNA in different blood cell fractions}

From the four blood samples collected from the 44-year old healthy male, we found that only PBMCs that were not treated with trypsin were HPV positive (Table 2).

The first blood sample was not trypsin-treated and B cells were separated from the rest of the PBMCs with magnetic bead sorting. Both the B cell fraction and the other PBMCs were found to be HPV DNA positive for a skin HPV type, HPV-FADI3.

Cells from the second blood collection were treated with trypsin before the PBMCs were separated into seven different fractions (B cells, myeloid dendritic cells, T cells, NK cells, macrophages and monocytes, neutrophils and flow-through). The serum and the seven cell fractions were all HPV DNA negative.

In the third blood sample, we found that the PBMCs that were treated with trypsin were HPV DNA negative, while those that were not trypsinised before DNA extraction were HPV DNA positive for HPV-FADI3. 
The fourth blood sample was not treated with trypsin and after serum (containing platelets) and red blood cells had been collected, the PBMCs were separated into eight different fractions (B cells, myeloid dendritic cells, plasmacytoid dendritic cells, T cells, NK cells, macrophages and monocytes, neutrophils and flow-through). We found three different cutaneous HPV types in the five HPV DNA positive blood cell fractions: HPV-FADI3 was isolated in the B cells, the myeloid dendritic cells and the flow-through fractions; NK cells were found to contain HPV vs73-1; and HPV-111 was isolated from the neutrophil fraction. The plasmacytoid dendritic cells, T cells, macrophages \& monocytes, red blood cell pellet and serum were all HPV DNA negative for FAP PCR.

All skin swabs from the antecubital site (before and after the tape-strip method) and the forehead were HPV DNA negative. The swab samples from the needles were also HPV DNA negative. 


\section{Discussion}

Certain high-risk HPV types have been recognized as the causative agents of $99.7 \%$ of all cervical cancers (25). High-risk HPV, in particular HPV-16 has been detected in anogenital cancers (other than cervical), and in esophageal, oropharyngeal and oral squamous cell carcinoma (6, 13, 14, 27). Other studies have reported HPV findings in cancers that occur at sites where direct HPV infection is usually not seen, including colorectal, lung and breast cancer $(5,7,16)$. Detection of HPV in cancers like this raises the question how HPV got to the site of cancer. One possibility is that it was transported in blood, and HPV DNA has indeed been reported to be found in peripheral blood mononuclear cells (PBMCs), sera and plasma (3, 9). We found 8.3\% (15/180) of our healthy blood donors to be HPV positive. Half of the HPV types detected in the PBMCs were skin HPV types that are commonly found in asymptomatic infections of normal, healthy skin $(1,4)$. The rest were high-risk HPV types that are associated with cancer development were detected in 1.7\% (3/180) of the samples. HPV is estimated to cause $3-5 \%$ of all human cancers (19) and, although the numbers are small in this study, this HPV DNA prevalence in healthy males merits further investigation. While previous studies have suggested that HPV DNA in blood originated from cervical cancer cells $(9,23,24)$, this would not explain our findings since participants in our study were male blood donors. However, participants in this study were healthy blood donating men, although due to the anonymous collection of blood we cannot exclude the possibility that the healthy male blood donors had a type of cancer caused by HPV, like penile or oral squamous cell carcinoma $(13,14)$.

HPV DNA was only detected in blood when we analysed PBMCs that had not been treated with trypsin. Therefore, HPV appears to be attached to the PBMCs by a cell surface protein. It has previously been shown that PV virions can bind to a wide range of cell types from different species (20) and our data suggest that HPV is attached to the cell surface of the PBMCs and is not taken up by the cell. $\alpha 6$ integrin receptors have been suggested to bind and mediate uptake of the virus particles into the cells (11). T cells and platelets express $\alpha 6$ integrin receptors (26), however the serum and $\mathrm{T}$ cell 
fractions in our study were HPV DNA negative. Our results showed a widespread distribution of different HPV types in various blood cell types, suggesting that the HPV virions tend to attach more to some types of PMBCs than others. We and others have shown that glycosaminoglycans are able to bind HPV with low affinity $(10,15)$. Furthermore, to identify which specific receptors mediates the uptake of HPV into peripheral blood is important.

Our results provide evidence that HPV cannot only be spread through sexual contacts, skin abrasions or close contacts, but also via a new route where it enters the peripheral blood with the help of PBMCs. According to our present state of knowledge, replication of HPV is strictly synchronized with the life cycle of mucosal or cutaneous epithelial cells (22), however the presence of HPV DNA in blood, including high risk HPV types, suggests that further studies are needed to elucidate whether HPV virions can be transmitted through blood transfusion. Furthermore, the potential of blood being the vehicle for HPV to infect at other body organs has still yet to be determined.

\section{Acknowledgements}

This work was supported by the Prostate Cancer Foundation in Australia, the Mazda foundation and the Sir Edward Dunlop Medical Research Foundation. We would like to thank Dr. Astrid Lefringhausen from Miltenyi Biotec Australia, for help with the blood cell separation protocols. Thanks are also due to all the Australian Red Cross Blood Services (ARCBS) donors who participated as healthy controls in this study, Rachelle Morris and the staff at the ARCBS for their assistance with the collection of risk factor information and blood samples, and Joanne Young, Melanie Higgins, Kimberly Hinze, Robert Smith, and members of the Molecular Cancer Epidemiology Laboratory, for their assistance with collection and processing of blood samples. 


\section{References}

1. Antonsson, A., O. Forslund, H. Ekberg, G. Sterner, and B. G. Hansson. 2000. The ubiquity and impressive genomic diversity of human skin papillomaviruses suggest a commensalic nature of these viruses. J Virol 74:11636-41.

2. Antonsson, A., S. Karanfilovska, P. G. Lindqvist, and B. G. Hansson. 2003. General acquisition of human papillomavirus infections of skin occurs in early infancy. J Clin Microbiol 41:2509-14.

3. Bodaghi, S., L. V. Wood, G. Roby, C. Ryder, S. M. Steinberg, and Z. M. Zheng. 2005. Could human papillomaviruses be spread through blood? J Clin Microbiol 43:5428-34.

4. Chen, A. C.-H., N. A. J. McMillan, and A. Antonsson. 2008. Human papillomavirus type spectrum in normal skin of individuals with or without a history of frequent sun exposure. J Gen Virol 89:2891-7.

5. Cheng, Y. W., M. F. Wu, J. Wang, K. T. Yeh, Y. G. Goan, H. L. Chiou, C. Y. Chen, and H. Lee. 2007. Human papillomavirus 16/18 E6 oncoprotein is expressed in lung cancer and related with p53 inactivation. Cancer Res 67:10686-93.

6. D'Souza, G., A. R. Kreimer, R. Viscidi, M. Pawlita, C. Fakhry, W. M. Koch, W. H. Westra, and M. L. Gillison. 2007. Case-control study of human papillomavirus and oropharyngeal cancer. N Engl J Med 356:1944-56.

7. Damin, D. C., M. B. Caetano, M. A. Rosito, G. Schwartsmann, A. S. Damin, A. P. Frazzon, R. D. Ruppenthal, and C. O. Alexandre. 2007. Evidence for an association of human papillomavirus infection and colorectal cancer. Eur J Surg Oncol 33:569-74.

8. Deragon, J. M., D. Sinnett, G. Mitchell, M. Potier, and D. Labuda. 1990. Use of gamma irradiation to eliminate DNA contamination for PCR. Nucleic Acids Res 18:6149.

9. Dong, S. M., S. I. Pai, S. H. Rha, A. Hildesheim, R. J. Kurman, P. E. Schwartz, R. Mortel, L. McGowan, M. D. Greenberg, W. A. Barnes, and D. Sidransky. 2002. Detection 
and quantitation of human papillomavirus DNA in the plasma of patients with cervical carcinoma. Cancer Epidemiol Biomarkers Prev 11:3-6.

10. Drobni, P., N. Mistry, N. McMillan, and M. Evander. 2003. Carboxy-fluorescein diacetate, succinimidyl ester labeled papillomavirus virus-like particles fluoresce after internalization and interact with heparan sulfate for binding and entry. Virology 310:163-72.

11. Evander, M., I. H. Frazer, E. Payne, Y. M. Qi, K. Hengst, and N. A. McMillan. 1997. Identification of the alpha6 integrin as a candidate receptor for papillomaviruses. J Virol 71:2449-56.

12. Forslund, O., A. Antonsson, P. Nordin, B. Stenquist, and B. G. Hansson. 1999. A broad range of human papillomavirus types detected with a general PCR method suitable for analysis of cutaneous tumours and normal skin. J Gen Virol 80:2437-43.

13. Hansson, B. G., K. Rosenquist, A. Antonsson, J. Wennerberg, E. B. Schildt, A. Bladstrom, and G. Andersson. 2005. Strong association between infection with human papillomavirus and oral and oropharyngeal squamous cell carcinoma: a population-based casecontrol study in southern Sweden. Acta Otolaryngol 125:1337-44.

14. Heideman, D. A., T. Waterboer, M. Pawlita, P. Delis-van Diemen, I. Nind1, J. A. Leijte, J. M. Bonfrer, S. Horenblas, C. J. Meijer, and P. J. Snijders. 2007. Human papillomavirus16 is the predominant type etiologically involved in penile squamous cell carcinoma. J Clin Oncol 25:4550-6.

15. Joyce, J. G., J. S. Tung, C. T. Przysiecki, J. C. Cook, E. D. Lehman, J. A. Sands, K. U. Jansen, and P. M. Keller. 1999. The L1 major capsid protein of human papillomavirus type 11 recombinant virus-like particles interacts with heparin and cell-surface glycosaminoglycans on human keratinocytes. J Biol Chem 274:5810-22.

16. Kan, C. Y., B. J. Iacopetta, J. S. Lawson, and N. J. Whitaker. 2005. Identification of human papillomavirus DNA gene sequences in human breast cancer. Br J Cancer 93:946-8. 
17. Lai, J., M. A. Kedda, K. Hinze, R. L. Smith, J. Yaxley, A. B. Spurdle, C. P. Morris, J. Harris, and J. A. Clements. 2007. PSA/KLK3 AREI promoter polymorphism alters androgen receptor binding and is associated with prostate cancer susceptibility. Carcinogenesis 28:1032-9.

18. Oriel, J. D. 1971. Natural history of genital warts. Br J Vener Dis 47:1-13.

19. Parkin, D. M. 2006. The global health burden of infection-associated cancers in the year 2002 . Int J Cancer 118:3030-44.

20. Roden, R. B., R. Kirnbauer, A. B. Jenson, D. R. Lowy, and J. T. Schiller. 1994. Interaction of papillomaviruses with the cell surface. J Virol 68:7260-6.

21. Rombaldi, R. L., E. P. Serafini, J. Mandelli, E. Zimmermann, and K. P. Losquiavo. 2008. Transplacental transmission of Human Papillomavirus. Virol J 5:106.

22. Stubenrauch, F., and L. A. Laimins. 1999. Human papillomavirus life cycle: active and latent phases. Semin Cancer Biol 9:379-86.

23. Tsai, H. J., Y. W. Peng, L. Y. Lin, M. C. Chou, H. Lee, and H. L. Chiou. 2005. An association between human papillomavirus 16/18 deoxyribonucleic acid in peripheral blood with p16 protein expression in neoplastic cervical lesions. Cancer Detect Prev 29:537-43.

24. Tseng, C. J., C. C. Pao, J. D. Lin, Y. K. Soong, J. H. Hong, and S. Hsueh. 1999. Detection of human papillomavirus types 16 and 18 mRNA in peripheral blood of advanced cervical cancer patients and its association with prognosis. J Clin Oncol 17:1391-6.

25. Walboomers, J. M., M. V. Jacobs, M. M. Manos, F. X. Bosch, J. A. Kummer, K. V. Shah, P. J. Snijders, J. Peto, C. J. Meijer, and N. Munoz. 1999. Human papillomavirus is a necessary cause of invasive cervical cancer worldwide. J Pathol 189:12-9.

26. Wang, H. H., T. Y. Lee, and C. Y. Lin. 2008. Integrins mediate adherence and migration of T lymphocytes on human peritoneal mesothelial cells. Kidney Int 74:808-16.

27. zur Hausen, H. 1999. Papillomaviruses in human cancers. Proc Assoc Am Physicians 111:5817. 


\section{Tables}

TABLE 1. HPV types isolated from the $15 \mathrm{HPV}$ DNA positive Australian Red Cross Blood Donors.

\begin{tabular}{|c|c|l|}
\hline $\begin{array}{c}\text { Age } \\
\text { (years) }\end{array}$ & HPV type & HPV genus \\
\hline 42 & HPV-16* & alpha (mucosal) \\
\hline 24 & HPV-18* & alpha \\
\hline 55 & HPV-18* & alpha \\
\hline 56 & HPV-27 & alpha \\
\hline 46 & HPV-32 & alpha \\
\hline 51 & HPV-70 & alpha \\
\hline 40 & HPV-97 & alpha \\
\hline 43 & HPV-102 & alpha \\
\hline 67 & HPV-12 & beta (cutaneous) \\
\hline 43 & HPV-15 & beta \\
\hline 62 & HPV-47 & beta \\
\hline 50 & HPV-48 & gamma (cutaneous) \\
\hline 35 & HPV-65 & gamma \\
\hline 44 & HPV-FA31 & gamma \\
\hline 48 & HPV-FA55 & gamma \\
\hline
\end{tabular}

*high risk HPV types 
TABLE 2. Four blood collections with different processing of PBMCs from a 44year-old healthy male.

\begin{tabular}{|c|c|c|c|c|c|}
\hline $\begin{array}{l}\text { Bleed } \\
\text { no. }\end{array}$ & $\begin{array}{l}\text { Date of } \\
\text { blood } \\
\text { collection }\end{array}$ & $\begin{array}{l}\text { Trypsin } \\
\text { treatment }\end{array}$ & Blood cell fractions & $\begin{array}{c}\text { HPV } \\
\text { positive }\end{array}$ & HPV type \\
\hline 1 & 4.09 .2008 & no & $\begin{array}{l}\text { B cells } \\
\text { Flow-through }\end{array}$ & $\begin{array}{l}+ \\
+\end{array}$ & $\begin{array}{l}\text { FADI3 } \\
\text { FADI3 }\end{array}$ \\
\hline 2 & 23.10 .2008 & yes & $\begin{array}{l}\text { B cells } \\
\text { Myeloid dendritic cells } \\
\text { T cells } \\
\text { NK cells } \\
\text { Macrophages \& } \\
\text { monocytes } \\
\text { Neutrophils } \\
\text { Flow-through } \\
\text { Serum }\end{array}$ & $\begin{array}{l}- \\
- \\
- \\
- \\
- \\
- \\
- \\
-\end{array}$ & \\
\hline 3 & 6.11 .2008 & $\begin{array}{l}\text { yes } \\
\text { no }\end{array}$ & $\begin{array}{l}\text { All PBMCs } \\
\text { All PBMCs }\end{array}$ & $\begin{array}{l}- \\
+\end{array}$ & FADI3 \\
\hline 4 & 4.12 .2008 & no & $\begin{array}{l}\text { B cells } \\
\text { Myeloid dendritic cells } \\
\text { Plasmacytoid dendritic } \\
\text { cells } \\
\text { T cells } \\
\text { NK cells } \\
\text { Macrophages \& } \\
\text { monocytes } \\
\text { Neutrophils } \\
\text { Flow-through } \\
\text { Red blood cell pellet } \\
\text { Serum }\end{array}$ & $\begin{array}{l}+ \\
- \\
+ \\
- \\
+ \\
- \\
+ \\
+ \\
- \\
-\end{array}$ & $\begin{array}{l}\text { FADI3 } \\
\text { FADI3 } \\
\text { HPV vs73-1 }\end{array}$ \\
\hline
\end{tabular}

